\title{
A DISCURSIVIDADE DO CLIQUE NA PRODUÇÁO DE SENTIDOS E SUJEITOS
}

\section{THE DISCURSIVITY OF THE CLICK ON THE PRODUCTION OF SENSE AND SUBJECTS}

\author{
Paula Chiaretti \\ Universidade do Vale do Sapucaí, UNIVÁS, Pouso Alegre, MG, Brasil
}

\begin{abstract}
Resumo: Apoiado na perspectiva teórico-metodológica da Análise de Discurso de filiação a Pêcheux, este trabalho busca analisar uma propaganda de um banco ("Corte os cliques da sua empresa"), que se apoia no uso de recursos tecnológicos para propor diferentes "soluçōes". Buscou-se compreender de que modo a discursividade do "clique" funciona produzindo sentidos de imediato, literalidade, exatidão, precisão, correspondência, enfim, efeitos de sentido que apelam à completude (de sujeito e de sentido). Ao mesmo tempo, tentou-se mostrar os deslocamentos de sentido de liberdade e flexibilidade para os de codificação e prescrição.
\end{abstract}

Palavras-chave: Discurso digital; Clique; Subjetividade.

Abstract: Supported by the theoretical and methodological perspective of Discourse Analysis funded by Pêcheux, this paper aims to analyze an advertisement for a bank ("Cut clicks in your company") which is based on the use of technology to achieve different "solutions". We sought to understand how the discourse of the "click" functions producing senses of immediateness, literalness, accuracy, precision, correspondence, short, effects of senses that appeal to completeness (of subject and sense). At the same time, this article tries to show possible displacement of senses of freedom and flexibility to coding and prescription.

Keywords: Digital discourse; Click; Subjectivity.

\section{Introduçáo}

"Adquirimos o hábito de viver antes de adquirir o de pensar"

(Albert Camus, em $\mathbf{O}$ mito de Sísifo)

Segundo Pêcheux (2009 [1975]), o conceito althusseriano de "ideologia em geral" permite pensar o "homem" como um "'animal ideológico', isto é, pensar em sua especificidade enquanto parte da natureza, no sentido espinosano do termo" (p. 138). O que significa pensar que o homem, como parte da natureza, deva ser considerado um "animal ideológico"? Estamos aqui diante da negação de uma essência ou de uma natureza humana que, 
entấo, somente poderiam ser entendidas a partir do modo como a ideologia se inscreve na história e na língua. Essa ideologia em geral se distingue das "ideologias" por não apresentar uma história, ou melhor, por estar sempre e em qualquer momento da história presente. Náo se trata mais do conceito de conjunto de ideias, mas de um processo incontornável que, de fato, produz sujeito. É isso que leva Althusser (1980 [1970]) e, em seguida, Pêcheux (2009 [1975]) à afirmação de que a ideologia é "omni-histórica”.

Falar sobre o caráter ideológico da existência humana é considerar, portanto, a sua materialidade, ou seja, o caráter histórico das diferentes práticas que produzem sentido em diferentes formaçôes sociais. Porque o homem náo apresenta (quase) nada de natural, é possível pensar que a retomada do conceito de "materialidade" se torna relevante para os objetivos desse trabalho que pretende, por meio da análise discursiva de uma propaganda de um banco, tratar da especificidade que se apresenta na materialidade do digital.

$\mathrm{Na}$ obra althusseriana, a materialidade está relacionada aos modos de produção em uma formaçáo social histórica concreta, sendo ao mesmo tempo a "base' (Basis: Marx) da luta de classes; e, simultaneamente, [...] a sua existência material” (ALTHUSSER, 1978 [1973], p. 28) e interessa à medida que se configura como um ponto de compreensáo da sociedade e dos movimentos da história. A consideração da materialidade pela Análise de Discurso apresenta outro objetivo: compreender a constituição dos sentidos. Por isso, o Materialismo Histórico não é a única disciplina que compóe o quadro da $\mathrm{AD}$ e nem mesmo é retomado sem reformulaçôes. Ela se apoia ainda em dois campos: na Linguística e na Teoria do Discurso, sendo essas três regióes "de certo modo, atravessadas e articuladas por uma teoria da subjetividade (de natureza psicanalítica)" (PÊCHEUX; FUCHS, 2010 [1975], p. 160).

Assim, na perspectiva da Análise de Discurso, o sujeito é constituído a partir de uma dupla determinação: da ideologia e do inconsciente. Essa dupla determinação, no entanto, não implica a possibilidade de que a constituição seja partida em duas determinaçóes distintas e independentes, uma vez que é propriamente a partir da consideração da hipótese do inconsciente que Althusser elabora a forma pela qual a ideologia interpela o indivíduo em sujeito. Baseado nesse processo de interpelação, no qual inconsciente e ideologia são igualmente imprescindíveis e inseparáveis na construção de evidências (de sujeito e sentido), Pêcheux propóe um modelo de análise discursiva que leve em consideração o "caráter material do sentido", ou seja, a determinação histórica e linguística do sentido. 
Dessa forma, o resultado desse processo é a constituição do sentido e do sujeito afetados pela língua e pela história. Isso nos permite buscar compreender os modos de subjetivação a partir não da sua descrição ou catalogação (como é possível ser feito nas ciências sociais e na Psicologia, por exemplo), mas a partir da compreensão do "modo" pelo qual o discurso se constitui. Mais precisamente, este trabalho busca compreender discursivamente o modo de subjetivação e o regime de "sociabilidade" (ou, ainda, a relaçáo entre os sujeitos constituídos historicamente) implicados no gesto do "clique", entendido, aqui, como discurso. Ao tomar a perspectiva discursiva como modo de abordar o clique, pretendemos nos distanciar de teorias que possam vir a compreender os procedimentos digitais (tais como o clicar) a partir de chaves interpretativas que buscam descrever e explicar comportamentos e sujeitos como atores sociais ou psicológicos. Pela consideração do discurso, aproximamo-nos da compreensão discursiva dos sentidos de "relação" entre sujeitos, como veremos adiante.

Ainda a respeito do conceito de materialidade que nos interessa aqui, Dias (2011, p. 19) escreve: "a forma como a sociedade contemporânea se mostra através de diferentes linguagens é efeito de um processo de significação do mundo que tem uma discursividade específica, um modo de inscrição histórica dos sentidos e dos sujeitos, uma materialidade". Considerar o clique como discurso implica supor que a partir de tal análise possamos compreender de que modo, atualmente, história e língua se inscrevem na constituição de sujeito e sentido, levando em consideração o lugar privilegiado que o discurso digital e o gesto do clique ocupam nas práticas cotidianas.

Os conceitos e dispositivos pertinentes para a compreensão de tal discurso náo podem ser pensados abstratamente. Isso porque a Análise de Discurso não é simplesmente uma teoria ou método, mas um modo específico de compreender os processos discursivos. Náo há análise de discurso sem análise. Se, por um lado, essa disciplina de entremeio (ORLANDI, 1996) se apoia em um modelo epistemológico próprio, descrito, como vimos, em Pêcheux e Fuchs (2010 [1975]), por outro lado, ela não pode desconsiderar a história e a evolução que a própria construção teórica sofre a partir das diversas análises que se empreendem na busca da compreensão dos processos históricos de significação. $\mathrm{O}$ discurso digital, discurso que se impóe globalmente a despeito de regimes políticos nacionais (democráticos, ditatoriais etc.), configura-se como um lugar privilegiado de análise, já que nos obriga a considerar o conceito de materialidade como aquilo que nos permite considerar a não-transparência da história. 
Assim, na perspectiva da Análise de Discurso, pensar o funcionamento da ideologia é supor que exista, de modo incontornável, divisão de sentidos e contradiçâa. É considerar, ainda, que todo sentido é político, pois se produz a partir de uma formaçáo social que náo é homogênea, mas que se caracteriza por relaçóes de dominação-resistência. E é precisamente por conta do modo como os sentidos se constituem que podemos considerar que "o sentido sempre pode vir a ser outro" (ORLANDI, 2013a).

\section{A discursividade do "clique"}

A busca de uma compreensão discursiva de elementos relacionados ao discurso digital tem se tornado cada vez mais presente no campo teórico da Análise de Discurso filiada a Michel Pêcheux. Por isso, o presente trabalho se apoia também no esforço anterior de pesquisadores da área (ORLANDI, 2013b; DIAS, 2009, 2011, 2013; MORELLO, 2003, NUNES, 2011, dentre outros). No que diz respeito de maneira mais estrita ao material de nossa análise, consideramos importante retomar alguns encaminhamentos teóricos que essas autoras propuseram.

Morello (2003), por exemplo, interessa-se pelo funcionamento do link, especialmente no que concerne à possibilidade de compreensão que nos oferece acerca do modo como funciona a definição em glossários, na medida em que compreende o link como "fato discursivo estruturador do processo de escrita do conhecimento em suas relaçoos possíveis" (MORELLO, 2003, p. 121). Assim, para a autora, o link, que vincula dois elementos, funcionaria a partir da existência imaginária da definiçấo. Também nesse trabalho, Morello (2003, p. 122) desloca o entendimento de link como simples procedimento técnico ou ainda de uma "via livre e purificadora (não menos democratizadora?!) do conhecimento - aquela pela qual todos e qualquer um pode/deve passar": ao contrário do sentido de neutralidade que se constitui no link, este produziria estabilização de sentidos, fixando evidências.

Nunes (2011) retoma o trabalho de Morello (2003) a fim de compreender o funcionamento do "clique-link". Preocupada com o funcionamento discursivo dos infográficos e com "gesto específico de clicar nos links", Nunes (2011) elabora o que chama de "injunção clique-link". Segundo a pesquisadora, "o link só funciona (só abre) se for clicado, e quem o clica é um sujeito” (NUNES, 2001, p. 1). Com a finalidade de dar conta do funcionamento discursivo presente no clique-link, a pesquisadora escolhe a palavra injunção, que aponta para a obrigatoriedade do gesto, fazendo do não clicar algo impossível. Só há uso do computador se há clique. 
No entanto, o nosso objeto de pesquisa neste trabalho, a saber, o "clique", na qualidade de comando específico que desencadeia um ou uma série - de procedimentos, não liga dois pontos ou espaços. Há, materialmente, algo que diferencia o link do comando (formulado no "clique"), como veremos adiante.

Podemos adiantar, além disso, que, atualmente, o clique se formula como absolutamente transparente, dada a frequência com que realizamos esse gesto, ao mesmo tempo em que absolutamente opaco, uma vez que seu modo de funcionamento escapa ao usuário. Graças à interface, um dispositivo de comunicaçáo entre dois sistemas, o computador passou do estatuto de "um instrumento de tortura baseado em comandos para um meio de empoderamento amigável ao usuário" (CHUN, 2011, p. 59, tradução nossa).

Podemos nos perguntar se "clicar", mover cursores, deslizar o dedo (touch) sob uma superfície encontraria alguma "naturalidade"? A "naturalidade" pressupóe, por sua vez, uma subjetividade universal. Entretanto, na perspectiva da Análise de Discurso, falar em subjetividade é supor o abandono do natural em prol de uma construção simbólica.

Para Pereira (2015, p. 43), “teclar e clicar são práticas sóciohistóricas que reorganizam textualmente o dizer, demandam gestos de leitura, interpretação e escrita". O autor, interessado na interface, propóe que esta seja entendida como um texto que deverá ser lido pelo usuário, constituindo-se também como um lugar de atualização do sujeito no qual deve estar previsto o equívoco e a opacidade.

Pensando-a, então, em termos de subjetividade, podemos considerar que o discurso digital se configura, portanto, como um lugar de compreensão da subjetividade. Segundo Orlandi (2001, p. 99), o interesse discursivo pela subjetividade nos leva a buscar "compreender como a língua acontece no homem”. Essa subjetividade se estrutura no acontecimento do discurso. É porque essa compreensão se dá via discurso que se descola de homem para sujeito, se distanciando, portanto, do campo das ciências sociais. Sujeito não seria, entâo, para nós, um ator social, mas uma "posição entre outras" (ORLANDI, 2001, p. 99).

\section{A campanha publicitária "Corte os cliques da sua empresa"}

Com o objetivo de compreender de que modo os sentidos se constituem no discurso digital, tomamos como material de análise uma das 
propagandas da campanha do banco Itaú intitulada "Corte os cliques da sua empresa”. A tela da propaganda principal dessa campanha, que apresenta o slogan, está dividida em dois espaços de trabalho simetricamente opostos e justapostos. Neles, dois funcionários trabalham, cada um à sua maneira, como pode ser observado na imagem abaixo:

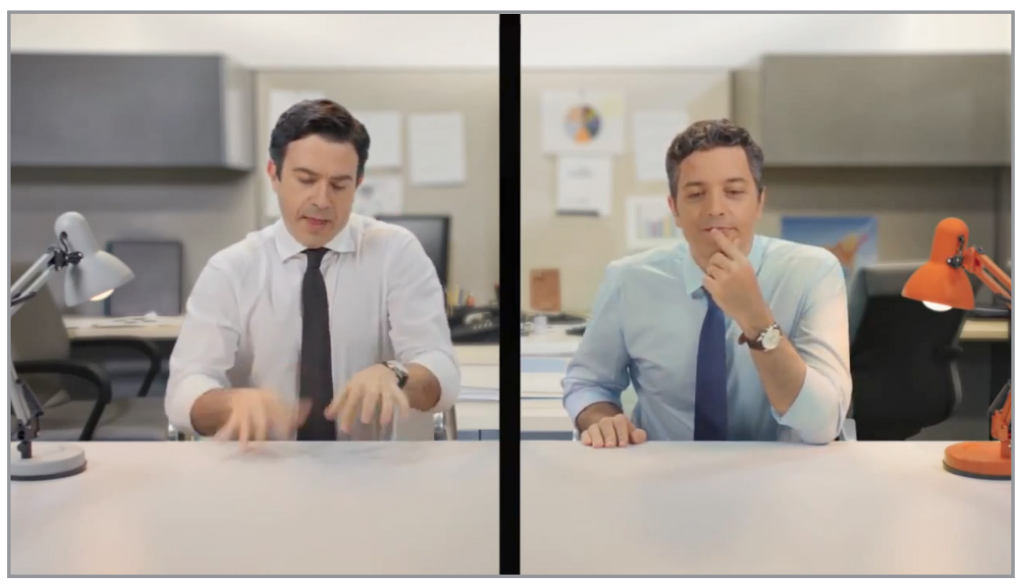

Figura 1: Funcionários.

Fonte: Youtube.

Interessa-nos observar o modo como cada um dos funcionários executa diferentes gestos a fim de cumprir as tarefas que supostamente são previstas em suas funçóes. As cores, marcadamente preta e branca do lado esquerdo e colorida do lado direito, poderiam nos indiciar sentidos que apontam para a "modernização". Na propaganda, é possível ouvir um narrador ao fundo que diz: "Corte os cliques da sua empresa. Experimente as soluçôes digitais do Itaú para deixar sua empresa mais ágil e simples".

A música da propaganda se intitula "Typewriter", do compositor americano Leroy Anderson, originalmente executada por uma orquestra com a participação de uma máquina de escrever entre os instrumentos musicais. De acordo com Jurandir Craveiro (2015), a propaganda é inspirada em uma cena em que o ator Jerry Lewis, no filme "Errado pra cachorro" (em inglês, "Who's minding the store?"), faz os movimentos de quem digita em uma máquina de escrever no ar, como podemos observar nos recortes de cena abaixo: 

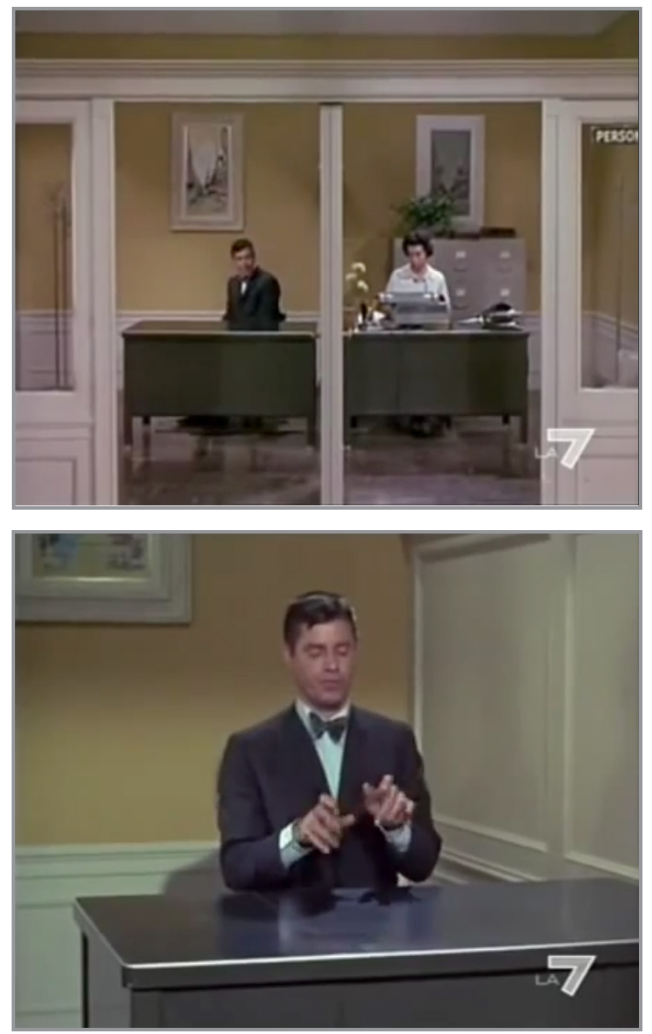

Figuras 2 e 3: Cena do filme em que o personagem Norman Phiffier (Jerry Lewis) finge digitar em uma máquina de escrever.

Fonte: Filme "Errado pra cachorro" (em inglês, "Who's minding the store?").

Por meio do conceito de intericonicidade, Courtine (2005), em entrevista a Nilton Milanez, sublinha o caráter discursivo da imagem. Falar em discurso, no lugar de língua, ou de representação, significa dar lugar àquilo que o discurso possui de característico: seu movimento de sentidos. Orlandi (2013a) afirma que o discurso é a palavra em movimento e, portanto, apartada de um sentido único e imutável, uma vez que este sempre pode vir a ser outro.

Voltando a Courtine (2005), uma imagem, assim como uma palavra, é interpretável a partir de uma dada memória. Para tanto, a imagem se inscreve no que ele chama de uma "cultura visual" que, por sua vez, pressupóe uma 
"memória visual", uma espécie de "eco". Ainda para o autor, essas imagens, que funcionam na memória possibilitando que outras imagens sejam interpretadas, podem se qualificar tanto como "história das imagens vistas" quanto como "história das imagens sugeridas". Trata-se, em todo caso, do "armazenamento" de imagens (existentes ou imaginadas). O pesquisador chega a falar em um "catálogo de imagens" - por parte do indivíduo. Essas imagens podem, portanto, ser colocadas em uma série, possibilitando ao analista trabalhar com uma genealogia da imagem, da mesma forma como Foucault coloca o funcionamento da rede de reformulaçáo.

Ainda que exista uma relação (de citação, talvez) entre as imagens, fortalecida pela presença de uma mesma música de fundo e pelo gesto de teclar "no ar", entre a propaganda analisada e a cena do filme "Errado pra cachorro", o desconhecimento de um não impossibilita a inteligibilidade de outro. Isso porque essa genealogia náo é algo que possa ser retraçado, exceto por um percurso possível, não necessário, entre duas imagens. Da mesma maneira, o trabalho de análise discursiva aponta para um percurso de um gesto de interpretação possível (dentre outros possíveis).

Observamos que há um deslocamento da cena do filme estrelado por Jerry Lewis e a propaganda do banco. Se, no primeiro, o quadro está divido entre uma pessoa (à direita) que de fato escreve à máquina, enquanto que a outra (à esquerda) imita o gesto em um tom jocoso, o que observamos na propaganda é que a tela se divide entre dois funcionários (que cumprem uma mesma funçáo em empresas diferentes?) que teclam sem que seja necessária a presença da máquina (seja ela de escrever ou um computador).

Nesse momento, podemos nos perguntar: os gestos de digitar na máquina de escrever e de acionar um comando por meio de um clique partilham uma materialidade? Se ao digitar em uma máquina de escrever, o resultado é a impressão de caracteres em uma página de papel, isso não garante que algo (uma operação financeira, por exemplo,) necessariamente se produza apenas por esse gesto de teclar. $\mathrm{O}$ gesto de teclar na máquina de escrever tem validade por ser legível e interpretável. Está previsto aí um espaço de interpretação e de leitura. O que observará, no caso do clique, é o efeito de "suficiência" produzido.

Passando à cena da propaganda do banco, que sentidos poderiam produzir os dois gestos de teclar justapostos? Haveríamos passado a regimes distintos de escrita e de produção de sentidos? Buscando compreender a relaçáo entre diferentes tecnologias e a produção do conhecimento, Dias (2009) retoma diferentes gestos, estabelecendo as seguintes relaçóes com suas épocas: 


$$
\begin{aligned}
& \text { falar }=\text { voz (cultura oral) } \\
& \text { escrever }=\text { manuscrito (cultura do manuscrito) } \\
& \left.\begin{array}{l}
\text { digitar }=\text { digitus } \\
\text { teclar }=\text { tecla }
\end{array}\right\} \text { (cultura digital) } \\
& \text { (DIAS, 2009, p. 10). }
\end{aligned}
$$

À série proposta pela autora, gostaríamos de acrescentar o "clicar", cuja escrita recorre a protocolos previamente formalizados pela programação. Enquanto o funcionário da esquerda tecla ininterruptamente, o funcionário da direita efetua poucos cliques que parecem estar em posição de equivalência aos incontáveis toques do primeiro. Poderíamos até mesmo arriscar a interpretação de que o funcionário da esquerda "tecla discursivamente", enquanto que o funcionário da direita "aciona comandos".

Haveria no "comando" uma programação específica que prevê um percurso e uma consequência. Isso o distingue do link, vínculo, que liga um espaço ao outro no digital. O clique, que nos interessa aqui, é aquele a partir do qual uma "açáo" toma lugar. Esta ação está relacionada à administração das relaçóes entre os sujeitos - engendram novos sentidos para a sociedade e para o sujeito. Como se deve gastar ou aplicar os recursos de uma empresa? Náo se trata aqui de uma escolha neutra, mas sim de uma questáo política que é colocada, pela propaganda em questão, como uma questáo relacionada apenas à "comodidade", à "agilidade", à "conveniência", à "técnica". "Basta um clique", o efeito de sentido de suficiência que se constitui aí aponta para uma direção na qual o caráter político do gesto (tenta) se apagar.

Dois modos distintos de clicar se constituem: um dentro do aplicativo (ou do banco Itaú) em que o "clique" é preciso, exato; e, outro, fora do banco, no qual o teclar significa perda de tempo e grande dispêndio de energia de funcionários (ou melhor, recursos da empresa).

Destaca-se, portanto, da discursividade do "clique", seu efeito de sentido (efeito imaginário) de literalidade. Náo há espaço dissertativo no "clique", ele existe ou náo. Os encaminhamentos previstos raramente são negociados. Podemos considerar que há um espaço programado para a (resoluçấo) da ambiguidade quando clicamos em um link em uma página da internet e podemos considerar a escolha entre: "abrir o link em uma nova guia", "abrir o link em uma nova janela", "salvar o link como", mas, novamente, as opçóes tendem a ser "exaustivas".

Isso nos permite considerar o funcionamento do esquecimento número 2 na discursividade do clique. Esse esquecimento, ligado à literalidade do dizer, possibilita-nos compreender como o "clique" se configuraria como a 
melhor forma possível de dizer algo, ou melhor, de executar uma ação ou de formular o procedimento. Podemos, a partir daí, compreender o "clique" como "formulaçáo", como a colocação em texto de um discurso e, mais propriamente, como um enunciado cuja natureza é bastante específica. As duas cenas justapostas em uma mesma tela se configuram como uma rede de reformulações de um mesmo "trabalho", o gerenciamento de uma empresa. O que distingue um esforço do outro é precisão (ou a ambiguidade) de cada um dos cliques.

Se nos propuséssemos a realizar uma análise pragmática desse objeto, o clique como enunciado, talvez pudéssemos classificá-lo como um performativo, isto é, um tipo de "proferimento" que não descreva, nem relate, nem constate algo, ou ainda, que não seja classificado como "verdadeiro" ou "falso". Cabem aqui parênteses: nesse exercício, é preciso ainda que coloquemos em suspenso nossa suspeita sobre a existência de "declaraçôes" ou de "descriçôes". Para satisfazer à condição de performativo, é necessário, ainda, que "o proferimento da sentença [...] [seja], no todo ou em parte, a realizaçáo de uma ação, que não seria normalmente descrita consistindo em dizer algo" (AUSTIN, 1990 [1962], p. 24). De fato, o que nos interessa aqui é menos a classificação que uma orientação de sentido que pode ser considerada a respeito de enunciados que "realizam uma açáo". Assim, podemos considerar que essa observação nos auxilia a descrever os traços que nos possibilitam compreender o funcionamento discursivo do "clique" - a equivalência do enunciado do clique à "realização da açáo". Frequentemente, no espaço digital, deparamo-nos com enunciados cujo funcionamento aponta para essa direção de sentido - de realização de uma ação -, como os possíveis cliques abaixo: 


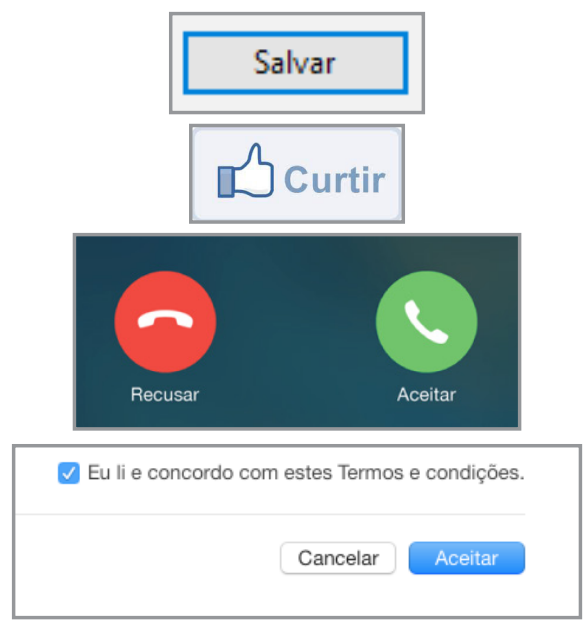

Figura 4: Cliques.

Fonte: Facebook.

\section{Um último traço formal do performativo que nos interessa:} de acordo com Austin (1990 [1962]), este tipo de enunciado (ou de "proferimento", como escreve) faz uso da primeira pessoa do singular no presente do indicativo: "'Aceito [...] esta mulher como minha legítima esposa' - do modo que é proferido no decurso de uma cerimônia de casamento [...] 'Lego a meu irmáo este relógio' - tal como ocorre em um testamento" (AUSTIN, 1990 [1962], p. 24). A partir do gesto do clique, da constituição do sujeito que clica, ocupando e colocando em funcionamento um préconstruído (previsto pela programação), os enunciados que aparecem no botâo de clique no infinitivo ("salvar", "curtir", etc.) são reformulados para: "salvo", “curto", “recuso" ou "aceito” (uma ligação), e, por fim, "aceito" (cujo peso do ponto de vista jurídico é algo que talvez mereça por si só outro trabalho posteriormente). Em todo caso, há uma regularidade que os une: trata-se de realizar, de operar, de efetuar - daí a importância do conceito de materialidade e de sua retomada pela perspectiva discursiva na compreensão do processo de significação desse enunciado.

Mas, afinal, o que se realizaria nesse discurso?

\section{"Soluçáo" x "prescriçáo"}

Para as disciplinas técnicas, os avanços tecnológicos são usualmente 
tomados como "soluçóes", "avanços", descartando (ou pelo menos colocando em um segundo plano) o seu caráter político e até mesmo prescritivo, como observaremos a seguir.

A parte final da propaganda faz apelo à condensação de procedimentos/ comandos que é oferecida como produto pelo banco.
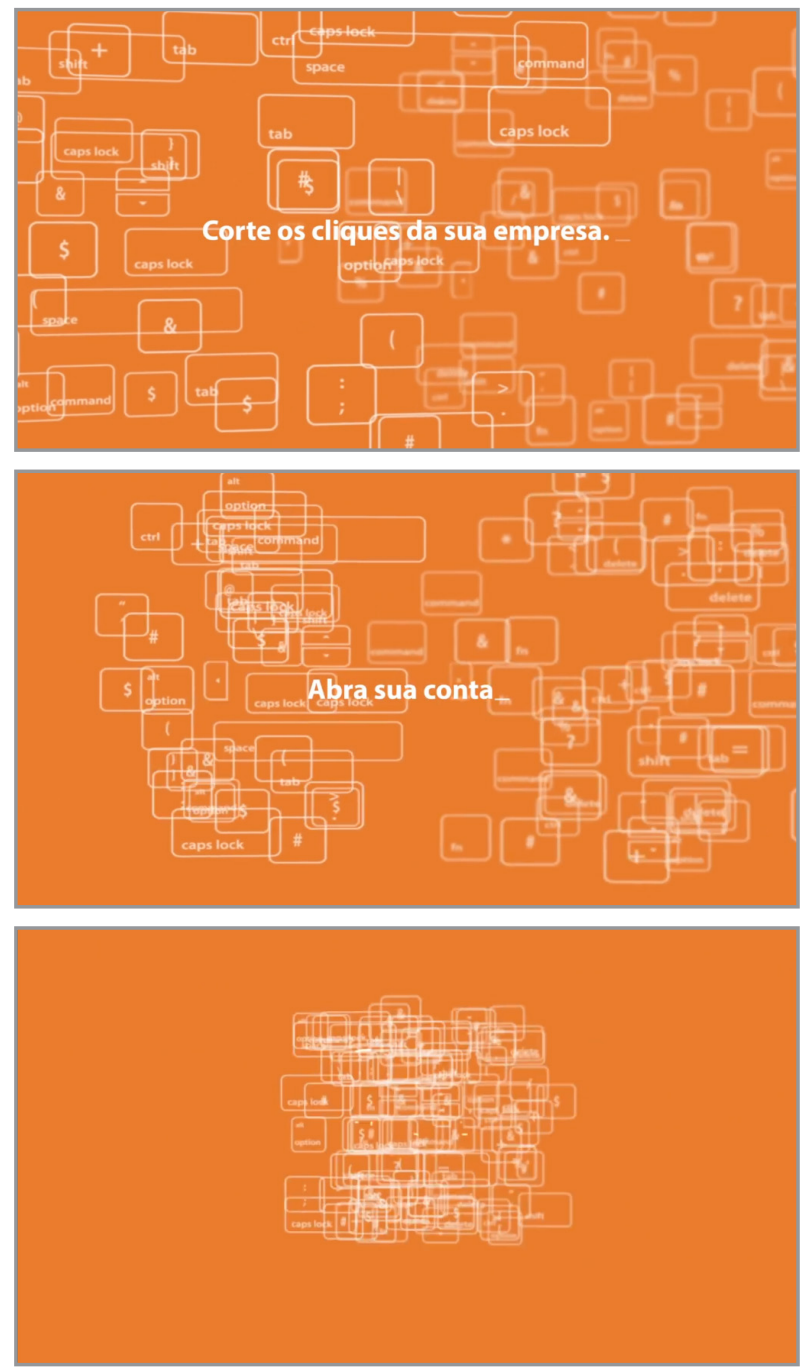

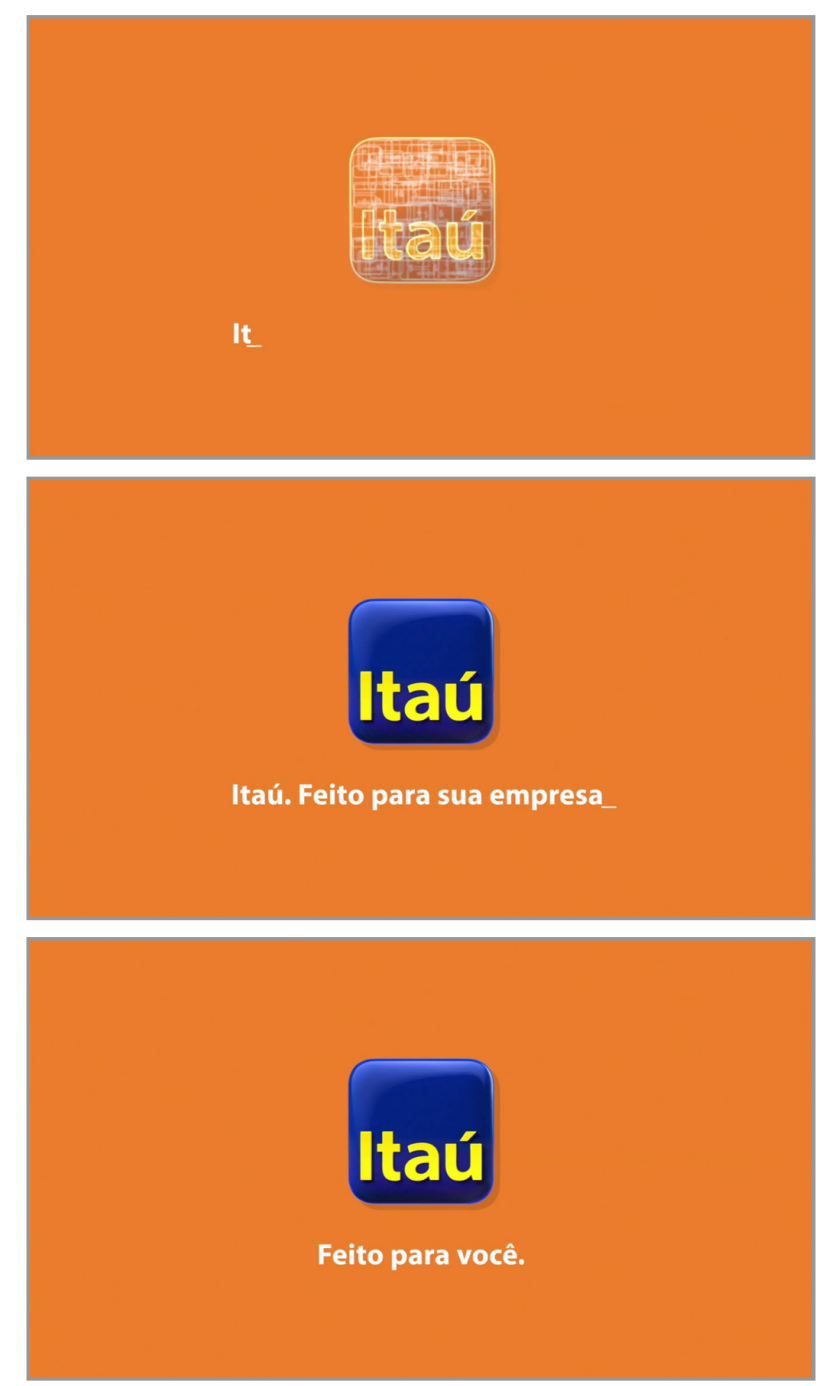

Figura 5: Itaú. Nesta sequência de seis prints de tela da propaganda, diversos "cliques" se condensam no logotipo do banco.

Fonte: Site Itaú. 
Considerando que a animação possa ser tomada por sua sintaxe própria, na qual os diferentes elementos possam ser entendidos em seu funcionamento de construção de um predicado, diversos "botôes/teclas" (“caps lock”, “tab”, “\$”, “+”, “enter”) convergem em um único (e, portanto, exato) "botáo/tecla/clique" ("Itaú"). O movimento pelo qual os diversos comandos e símbolos convergem pode ser descrito como um movimento centrípeto que os aglutina, condensa-os, para que depois se apaguem, dando, entáo, lugar (ou sendo substituídos por) um logotipo, o do Itaú.

Podemos nos perguntar: o que torna possível um processo de substituição em que um logotipo possa vir a ocupar o lugar (e executar a funçáo?) de todas as teclas? A própria existência das diferentes teclas em um teclado é frequentemente tomada como óbvia e evidente, mas basta que consideremos a existência de teclados em diferentes línguas e afins (PortuguêsBrasil, Português-Portugal, Inglês-EUA, Emoji) nos computadores e dispositivos móveis para nos perguntarmos sobre os processos de produção de evidência de sentido e de transparência da linguagem.

$\mathrm{Na}$ animação da propaganda, o movimento de aglutinação de diferentes teclas (símbolos e comandos), metaforizadas em seguida pelo logotipo do banco, produz efeitos de sentido de exatidão, precisão, suficiência do comando - do clique. Mas o que garante esse efeito? Que movimento na história é esse que sofrem os diferentes modos de fazer com a empresa que podem, a partir de agora, ser "condensados" em poucos cliques?

A empresa responsável pela criação do vídeo, a agência DM9DDB, escreveu em seu site que:

[...] segundo Fernando Amaral, diretor de Marketing Varejo do Itaú Unibanco, há uma necessidade imediata dos clientes por soluçóes digitais que contribuam para a eficiência dos processos 'Há uma mudança de comportamento também nos clientes pessoa jurídica, que precisam de agilidade e comodidade no dia a dia de suas empresas', ressalta o executivo (DM9DDB, 2015b, grifos nossos).

Como podemos entender essa promessa de "agilidade e comodidade"? Justificando-se pela "solução de problemas", ou simplesmente por "soluções", os comandos sáo propostos de modo a apagar outros comandos (ou formulaçóes ou enunciados) possíveis, produzindo, pela contenção da deriva, um sentido estável e único, cujo alcance é imediato (ou melhor, "ao alcance de um clique") para o cliente. Segundo Dias (2009), a instantaneidade do clique reconfigura as relaçóes de poder.

Os gestos do funcionário à direita, precisos, econômicos e diretamente 
sobre a "tela" (concretamente ausente, mas presente no gesto) fazem ainda apelo à tecnologia de manipulação direta, ou touch, na qual interface se apaga com ainda maior eficiência. De acordo com Negroponte (1995, p. 93), "é nisso que reside o segredo do projeto de uma interface: fazê-la desaparecer". O imediato e a instantaneidade sáo efeitos da materialidade específica do digital.

Pereira (2015, p. 35) ressalta a importância de que a interface não lembre ao usuário "a existência de toda a complexidade técnica, tanto eletrônica quanto de programação, existente por trás daquele objeto, e, assim, [dê]-lhe a sensação de falta de limite e de instantaneidade de acesso e comunicação, bem como de objetividade da linguagem".

É interessante ressaltar, ainda, o caráter prescritivo desse discurso que, ao produzir um sentido estável e homogêneo, prevê um sujeito (contemporâneo ao sentido) também estável e homogêneo, apontando, portanto, para um modo específico de subjetivação, "solucionada" e "prescrita" pelo clique. Podemos, no entanto, a despeito da aparente estabilidade da subjetividade prevista nesse discurso, apontar para algumas das pistas que indicam uma ambiguidade, ou, ainda, uma ruptura na estabilidade dos sentidos.

Ao mesmo tempo em que os comandos ou "protocolos de sociabilidade" são disponibilizados "ao alcance de um clique", sendo esse clique náoreformulável, é possível observar enunciados cujos sentidos apontam para outra direção: aquela da liberdade e da customização/personalização. Ainda de acordo com agência responsável pelas campanhas do banco, referindose a outra campanha, a campanha "Itaú Uniclass", o diretor de Marketing e Varejo do banco afirma que buscam atender seus clientes, por meio da utilização de recursos tecnológicos, "da maneira mais conveniente possível. 'E é exatamente isso que tentamos trazer para a campanha, mostrando que o cliente pode ser atendido da maneira que ele quiser" (DM9DDB, 2015a, grifos nossos).

"Do modo como o cliente quiser": essa orientaçấo de sentido pode ainda ser observada no seguinte recorte: 


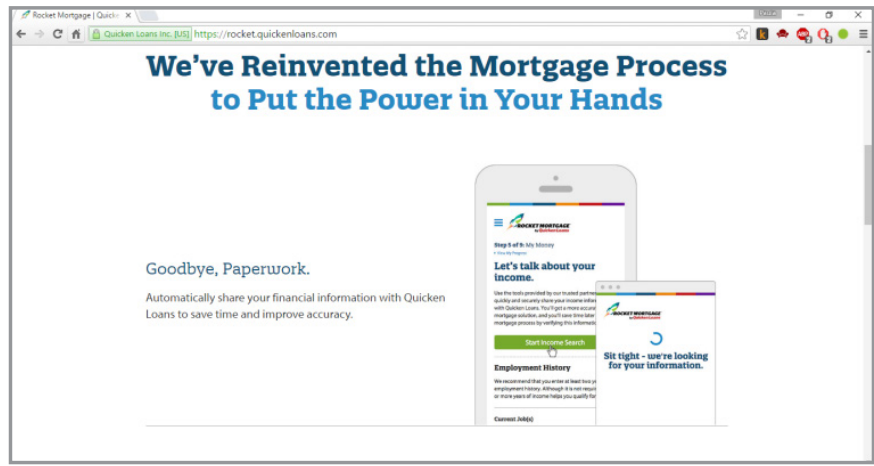

Figura 6: Página.

Fonte: Rocket ${ }^{1}$.

Lê-se no anúncio: "Nós reinventamos o processo de hipoteca para colocar o poder em suas mãos".

Ou ainda em:

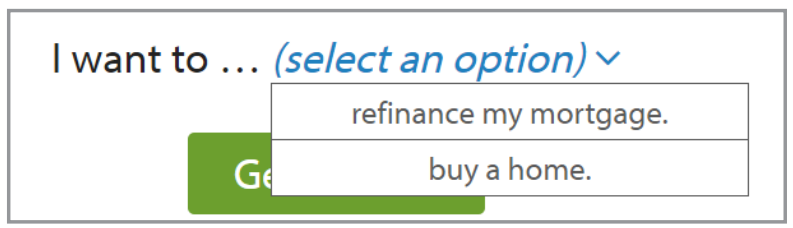

Figura 6: Recorte.

Fonte: Rocket ${ }^{2}$.

Em que se lê: "Eu quero... (selecionar uma opção)". O artigo indefinido "uma" presente no enunciado poderia colocar em funcionamento o sentido de "qualquer uma", no entanto, cabe ao usuário optar entre ("qualquer uma das") duas opçôes.

Observa-se, assim, que tais construçóes produziriam, além dos sentidos de aparente completude, um efeito de sentido de um "atalho" à satisfação total e completa. A possibilidade de clicar de qualquer lugar em que se encontre (claro, desde que internet, sinal, bateria, compatibilidade com o dispositivo utilizado etc. não sejam obstáculos ao projeto de completude), por meio da

1 Disponível em: <https://rocket.quickenloans.com/>. Acesso em: jan. 2017.

2 Disponível em: <https://rocket.quickenloans.com/>. Acesso em: jan. 2017. 
utilização do aplicativo do banco, seria decalcada em um segundo sentido: "tudo é possível". Nas palavras do diretor de Marketing, "ele [o cliente] pode ser atendido da maneira que ele quiser", mas cabe complementar: desde que essa maneira esteja prevista pelo aplicativo.

A própria formulação em clique promove um apagamento de toda e qualquer outra formulação possível, dando ainda maior força ao efeito de completude e de suficiência. Assim, a contenção da deriva e da polissemia prevista pelo próprio aplicativo, cujos comandos e formas de "interação" já estão programados (previstos), é apagada, podendo ser (ilusoriamente) substituída por qualquer forma de interagir com o banco.

Ao discutir a questáo da liberdade e da igualdade entre os homens nas sociedades democráticas, Haroche (2005, p. 134) cita Tocqueville (1990, p. 17) que acredita que toda revolução teria como efeito aproximado "remeter os homens a si mesmos e abrir no espírito de cada um deles um espaço vazio e sem limites". Isso colocaria, segundo a autora, a dependência e a deferência (objeto central de seu trabalho) tradicionais apartadas da liberdade e da igualdade. Cada vez mais, os homens se distanciariam daquilo que lhes é demandado, aproximando-se daquilo que lhes é caro de acordo com o que pensam por si mesmos, uma moral própria e individual.

Haroche (2005, p. 133) descreve o habitante da democracia como sendo "agitado, apressado, intempestivo, autossuficiente, arrogante". No entanto, cabe-nos perguntar se, no discurso digital, a dependência (da qual supostamente haveríamos nos libertado) assume novas formas, maneiras mais sofisticadas de se impor ao homem, sobrepondo-se paradoxalmente aos sentidos de liberdade, comodidade, agilidade e soluçáo. Isso porque, ao mesmo tempo em que a discursividade do clique faz um apelo à liberdade, observa-se uma massiva e silenciosa prescrição e codificação das práticas sociais. Codificação esta que se torna (quase) onipresente em uma sociedade na qual as relaçôes entre seus indivíduos são frequentemente (e cada vez mais) mediadas por programaçôes - "enviar uma mensagem"; "gravar uma mensagem"; "curtir"; "desfazer amizade"; "ligar"; "adicionar a contatos" etc.

Considerando que os protocolos de sociabilidade estiveram sempre presentes na vida humana (que não é natural, mas ideológica, como vimos), podemos nos perguntar se estamos diante, não de uma ruptura, mas de uma mudança no que diz respeito aos "ritos de interação", compreendidos, por Haroche (2005), como regras de conduta que sempre estiveram presentes na vida em sociedade e que se organizam a partir de códigos cuja função é a de garantir conveniências e equidade. 


\section{Subjetividade e discurso digital}

Por fim nos perguntamos: o discurso digital poderia fornecer as coordenadas da subjetividade atual? Para que um sujeito se constitua ou que um sentido se produza, são necessárias determinadas condições materiais de produçáo de sentido e de sujeito. O que se apaga no "clique", e que buscamos resgatar por meio da análise desenvolvida neste trabalho, é a realização de um sujeito usuário padrão inscrito historicamente. Esse "clique" (enquanto discurso, sentido em movimento) faz retorno a conceitos como sujeito, sociedade, corpos, memória, enfim, àquelas noçôes às quais recorremos quando buscamos compreender a subjetividade.

Em "ao alcance de um clique", o detour da satisfaçáo suposta por Freud (2011 [1930]) em uma sociedade pautada pelo recalque da satisfação imediata em prol de uma satisfação mais duradoura parece haver sido suprimido, sendo sua lógica substituída por outra, relacionada ao "imediatismo" promovido (e supostamente garantido) pelas condiçôes materiais atuais relacionadas aos avanços no campo da tecnologia. A "democratização" do acesso à internet faz do 'tudo é possível' um apanágio de todos.

"Liberdade”, "flexibilidade”, "personalização" e "customização” guiam os sentidos relacionados às "soluçóes digitais". No entanto, ao mesmo tempo em que permitem abarcar uma enorme complexidade (programaçóes e procedimentos efetivos), engendram o sentido de uma enorme ignorância, não é preciso saber-saber, mas um saber-fazer.

Para Chun (2011, p. 59, tradução nossa), “[a liberdade] também coincide com as técnicas de gerenciamento neoliberais que fizeram dos trabalhadores mais flexíveis e inseguros, empoderados e deficientes (por ex., sempre necessitando de treinamento)" 3 . A autora aproxima o funcionamento de interfaces ao "da ideologia E sua crítica", em seu processo contraditório de visibilidade e invisibilidade, causalidade racional e pura ignorância. Os procedimentos são totalmente transparentes e imediatos por um lado, mas suas origens ou implicaçôes absolutamente (ou quase) ignoradas. Ao mesmo tempo em que a tecnologia dá poder ao usuário, ela mapeia o usuário pelo processo mesmo pelo qual ele comanda e controla, ou para retomar a origem do termo grego kybernete, ele governa. Assim, em nosso corpus, o modo como se formula o efeito de sentido relacionado à prática material do gesto

\footnotetext{
${ }^{3}$ It also coincides with neoliberal management techniques that have made workers both flexible and insecure, both empowered and wanting (e.g., always in need of training) (CHUN, 2011, p. 59).
} 
do clique faz eco ao sentido de "controle", ainda que o "quem" controla possa ser colocado em questionamento.

Aos programas que são recebidos com satisfação pelos usuários são usualmente atribuídos adjetivos tais como: mestria/controle, confiança, facilidade, competência em realizar as tarefas, prazer, dentre outros. Segundo Chun (2011, p. 63, tradução nossa), "manipulação direta faz isso colocando o problema do trabalho por meio da perspectiva do trabalhador - mais precisamente do trabalhador neoliberal que decide trabalhar - e recolocando os comandos com estruturas mais participantes"4. Eis o novo espírito do capitalismo: participação, flexibilidade, comodidade, habilidade para aprender novas tarefas, autocontrole, auto-organização, ao lado de um estado de insegurança e ansiedade sobre estar desconectado / rejeitado / abandonado / obsoleto.

Para abordar essa subjetividade, Dias (2013) retoma Lafontaine (2004) que propóe uma figura polimorfa do sujeito que chama de "informacional". Segundo Dias (2013), o modelo de sujeito proposto é pautado por um imaginário de completude (do sujeito e do sentido). À lógica dos instrumentos como extensão do corpo a autora propốe uma interessante inversão: a do corpo como extensão da máquina. Inversão que nos ajuda a compreender os constantes sentimentos relatados de rejeição, abandono, desconexão e angústia.

Portanto, para além dos sentidos de liberdade e de flexibilidade, estamos diante de sentimentos relacionados à angústia, que, para Lacan, diz respeito à presença do objeto, à falta da falta. Em certo sentido, tomando essa lógica a partir daquilo que a Psicanálise pode nos dizer sobre a angústia, poderíamos nos perguntar, então, se a conexão e o sentido de imediato, em sua onipresença, ameaçam justamente o sujeito desejante, sujeito da falta. Náo se trata de propor uma resolução nostálgica de retorno ao passado, mas de buscar refletir sobre os efeitos do discurso digital na constituição da subjetividade. Afinal, não há simples repetiçôes na história. É a impossibilidade de contornar o discurso digital que nos leva a uma última análise: uma paráfrase de "Corte os cliques" proposta pelo próprio banco Itaú.

\footnotetext{
${ }^{4}$ Direct manipulation does this by framing the problem of work from the perspective of the worker - more precisely of the neoliberal worker who decides to work — and by replacing commands with more participatory structures.
} 


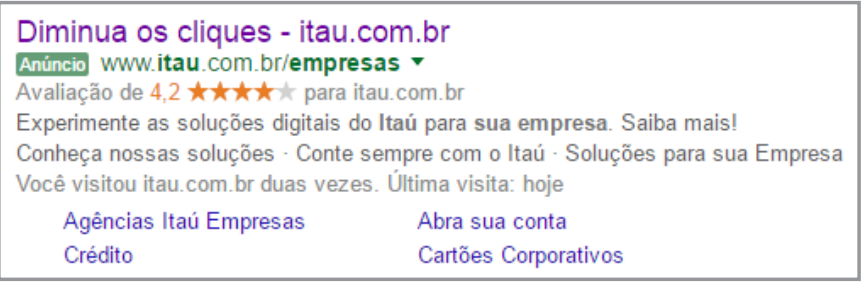

Figura 7: Pesquisa no Google de "Itaú corte os cliques".

Fonte: Google.

Não se trata mais de não haver clique, o que faria do digital (e toda a organizaçáo que já se assenta em seu funcionamento) absolutamente inexistente, mas, sim, de criar, visando à menor polissemia possível, uma interdição ao contingente. Assim, o efeito de sentido de controle das operaçóes financeiras (no caso específico do recorte analisado), cuja submissão a um modo específico de "gerenciamento" é apagada, produz, ao mesmo tempo, um sujeito "autônomo" e "livre" para clicar e realizar as operaçóes que ele acredita serem as melhores para o gerenciamento de sua empresa. Produz, ainda, um sujeito submetido "convenientemente" às codificaçóes de suas mais diversas práticas sociais impostas por meio da programação dos cliques. Assim, os produtos e serviços oferecidos se apagam, fazendo surgir um Universal que está relacionado, em última instância, aos imperativos de gestấo.

\section{Referências}

ALTHUSSER, L. Ideologia e aparelhos ideológicos do Estado. Lisboa: Presença, [1970] 1980.

. Posiçóes I. Rio de Janeiro: Graal, [1973] 1978.

CHUN, W. H. K. Programmed visions: sofware and memory. Cambridge: MIT Press, 2011.

COURTINE, J.-J. Intericonicidade - Entre(vista) com Jean-Jacques Courtine. Entrevistador: Nilton Milanez. Grudiocorpo. Out. de 2005. Disponível em: <http://grudiocorpo.blogspot.com/2009/06/ intericonicidade-entrevista-com-jean.html>. Acesso em: 20 jul. 2016.

CRAVEIRO, J. Comercial do Itaú se inspira em Jerry Lewis. 2015. Disponível em: <http://jura.com.br/itau-se-inspira-em-jerry-lewis/>. 
Acesso em: 20 jul. 2016.

DIAS, C. Sujeito digital: sentidos de um novo paradigma. In: GUIMARAES, E. (Org.) Cidade, Linguagem e Tecnologia: 20 anos de História. Campinas: LABEURB, 2013. p. 51-64. Disponível em: <http://www.labeurb.unicamp. br/labeurb20anos/labeurb20anosPDF.pdf $>$. Acesso em: 20 ago. 2016.

e-Urbano: a forma material do eletrônico no urbano. In. DIAS, Cristiane. E-urbano: Sentidos do espaço urbano/digital [online]. 2011. Consultada no Portal Labeurb - Laboratório de Estudos Urbanos. Disponível em: <http://www.labeurb.unicamp.br/livroEurbano/>. Acesso em: 20 ago. 2016.

A escrita como tecnologia de linguagem. Coleçáo HiperS@beres. Santa Maria, Universidade Federal de Santa Maria, v. II, dez. 2009. p. 7-17. Disponível em: <http://w3.ufsm.br/hipersaberes/volumeII/textos pdf/ TXTS PDF/cristiane dias.pdf>. Acesso em: 20 ago. 2016.

DM9DDB. Itaú amplia modelo de relacionamento $100 \%$ digital para os clientes Itaú Class. 2015a. Disponível em: <http://www.dm9ddb.com. br/?p=4189>. Acesso em 17 de julho de 2016.

- Itaú apresenta soluçóes digitais para empresas em nova campanha. 2015b. Disponível em: <http://www.dm9ddb.com. br/?p=4229>. Acesso em: 19 jul. 2016.

FREUD, S. O mal-estar na civilização. In: Obras psicológicas completas de

Sigmund Freud: Edição Standard Brasileira, v. XX. Rio de Janeiro: Imago, [1930] 2011.

HAROCHE, C. O comportamento de deferência: do cortesão à personalidade democrática. História: Questóes e debates. Curitiba, Editora UFPR, n. 42, p. 115-139. 2005.

NEGROPONTE, N. A vida digital. São Paulo: Companhia das Letras, 1995.

NUNES, S. R. O discurso do infográfico e a produção de uma posiçãosujeito leitor de informação infografada. Revista Ecos, v. 15, Ano X, n. 02. p. 323-342. 2013. Disponível em: <http://periodicos.unemat.br/index. php/ecos/article/view/643>. Acesso em: 15 mai. 2016. 
A injunção clique-link como forma material no infográfico eletrônico: trajetos de leitura. In: Anais do V SEAD - Seminário de Estudos em Análise do Discurso [recurso eletrônico] - Porto Alegre: Instituto de Letras da UFRGS, 2011. Disponível em: <http://www.ufrgs.br/ analisedodiscurso/anaisdosead/5SEAD/SIMPOSIOS/SilviaReginaNunes. pdf $>$. Acesso em: 20 ago. 2016.

ORLANDI, E. P. Análise de discurso: princípios e procedimentos. Campinas: Pontes, 2013a.

. A materialidade do gesto de interpretação e o discurso eletrônico. In. DIAS, Cristiane. Formas de mobilidade no espaço e-urbano: sentido e materialidade digital [online]. Série e-urbano. v. 2, 2013b. Consultada no Portal Labeurb - Laboratório de Estudos Urbanos. Disponível em: <http:// www.labeurb.unicamp.br/livroEurbano/>. Acesso em: 20 ago. 2016.

. Discurso e texto: formulação e circulação dos sentidos. Campinas: Pontes, 2001.

. Interpretaçáo: autoria, leitura e efeitos do trabalho simbólico. Petrópolis: Vozes, 1996.

PECHEUX, M.; FUCHS, C. A propósito da análise automática do discurso: atualização e perspectivas. In: GADET, F; HAK, T. (Orgs.) Por uma análise automática do discurso: uma introdução à obra de Michel Pêcheux. Campinas: Editora da Unicamp, 2010. p. 159-249.

PEREIRA, B. F. A interface gráfica como lugar de constituição subjetiva. Revista DisSoL - Discurso, Sociedade e Linguagem. Pouso Alegre, ano II, n. 2, out., p. 28-46. 2015. Disponível em: <http://ojs.univas.edu.br/ index.php?journal $=$ revistadissol\&page $=$ article\&op $=$ view \&path $\% 5 \mathrm{~B} \% 5 \mathrm{D}=$ 40\&path\%5B\%5D=44>. Acesso em: 17 nov. 2016.

TOCQUEVILle, A. de. De la démocratie en Amérique. Paris: Vrin, 1990. 